\title{
Acquired central diabetes insipidus
}

INSERM

\section{Source}

INSERM. (1999). Orphanet: an online rare disease and orphan drug data base. Acquired central diabetes insipidus. ORPHA:95626

Acquired central diabetes insipidus (acquired CDI) is a subtype of central diabetes insipidus (CDI, see this term), characterized by polyuria and polydipsia, due to an idiopathic or secondary decrease in vasopressin (AVP) production. 